\title{
Temperature behaviour of viscous flow with proteins
}

\author{
Karol Monkos \\ Department of Biophysics, Medical University of Silesia, H. Jordana 19, 41-808 Zabrze 8, Poland
}

\begin{abstract}
The paper presents the results of viscosity determinations on aqueous solutions of different mammalian serum albumins at a wide range of concentrations and at temperatures ranging from $278 \mathrm{~K}$ to $318 \mathrm{~K}$. On the basis of these measurements and a modified Arrhenius equation, the functional dependence of the solution activation energy of viscous flow on temperature was established. The analysis of the results obtained shows that the activation energy decreases with increasing temperature according to a square function for solutions, water molecules, and the albumins studied. The rate at which the activation energy decreases with increasing temperature is different for each albumin and mainly depends on its hydrodynamic radius.
\end{abstract}

Key words: Activation energy - Viscosity - Modified Arrhenius equation - Hydrodynamic radius - Albumin

\section{Introduction}

Viscous flow of both pure liquids and solutions can be considered as a thermally activated diffusion process. Like other processes with an activation energy barrier, the dependence of viscosity on temperature can be described by an equation of Arrhenius-type, which has the following form:

$$
\eta=A \exp \left(\frac{\Delta E}{R T}\right)
$$

in which $\eta, \Delta E, R$ and $T$ are viscosity, activation energy of viscous flow, gas constant and absolute temperature, respectively. The pre-exponential factor $\mathrm{A}$ is considered to be independent or nearly independent of temperature. The above equation is still widely used for different liquids such as solutions of polysaccharides (Lopez da Silva et al. 1994; Jauregui et al. 1995; de Paula and Rodrigues 1995; Kar and Arslan 1999; de Vasconcelos et al. 2000; Desbrieres 2002; Durand 2007), proteins (Tiffany and Koretz 2002), supramolecular polymers (Knoben et al. 2007), colloidal suspensions (Gun'ko et al. 2006) and others (Hayakawa et al. 1991; Bourret et al. 1994; Kamimura et al. 2006; Magerramov et al. 2007). A very convenient way of data presentation in this case is plotting the viscosity versus $\mathrm{T}^{-1}$

Corespondence to: Karol Monkos, Department of Biophysics, Medical University of Silesia, H. Jordana 19, 41-808 Zabrze 8, Poland

E-mail: monkos@sum.edu.pl in a ln-normal plot. The activation energy of the viscous flow can then be calculated directly from the slope of the straight line in the Arrhenius plot. However, it is worth noting that the Arrhenius equation describes the viscositytemperature dependence only in a relatively narrow range of temperatures. Viscosity data, when taken at a sufficiently wide range of temperatures, show non-Arrhenius behavior of viscosity, i.e. the dependence of $\ln \eta$ on $\mathrm{T}^{-1}$ is non-linear. This is observed in aqueous solutions of proteins when the viscosity data are taken from the freezing point of a solution up to the temperature at which thermal denaturation of proteins occurs. In this case, the most useful relation connecting the viscosity with temperature is a somewhat modified Arrhenius formula (Monkos 1996), which was successfully applied to globular and non-globular proteins (Monkos 2007a). It appears that the modified Arrhenius formula allows establishing the functional dependence of the viscous flow activation energy on temperature, and it will be discussed for some mammalian serum albumins in aqueous solutions.

Albumins are the most abundant proteins of the mammalian circulatory system, but they are also present in other tissues like a gut, liver or muscle. In the circulatory system they fulfill several physiological functions, mainly as carriers of many low-polar metabolites and drugs and as principal contributors to colloid osmotic blood pressure. For understanding of these functions, the knowledge of conformation of native albumins, their hydrodynamic properties and, in particular, estimation of the energetic characteristics of 
their viscous flow is of crucial importance. In blood plasma albumins represent more than $50 \%$ of the total proteins and this corresponds to a concentration of about $42 \mathrm{~kg} / \mathrm{m}^{3}$ (Gelamo et al. 2002). Mammalian serum albumins are moderately large proteins, with nearly identical molecular mass of about $66.5 \mathrm{kDa}$ (Dokal et al. 1999). Their primary structure is constituted by a single polypeptide chain of about 580 amino-acid residues. Albumins from different mammals exhibit high amino-acid sequence identity with each other (Ho et al. 1993). Despite these similarities, some differences exist in the three-dimensional structure of the albumins. Moreover, their physicochemical properties in solution are quite different, which was demonstrated by different experimental techniques such as dielectric spectroscopy (Moser et al. 1966), liquid chromatography (Šoltés and Sebille 1997), electrophoresis (Miller and Gemeiner 1998), viscometry (Monkos 2005a, b), calorimetry and fluorescence anisotropy (Dimitrova et al. 2000; Ercelen et al. 2005), circular dichroism (Khan and Shabnum 2001) or fluorescence spectroscopy and modeling (Gelamo 2002).

In the present study, the results of viscosity measurements on aqueous solutions of human serum albumin (HSA), equine serum albumin (ESA), ovine serum albumin (OSA) and rabbit serum albumin (RSA) at temperatures ranging from $278 \mathrm{~K}$ to $318 \mathrm{~K}$ and over a wide range of concentrations are presented. For each albumin the viscosity-temperature dependence, for a fixed concentration, is analyzed on the basis of the three parameters modified Arrhenius formula. This formula allows determining the dependence of viscous flow activation energy on temperature. It appears that the activation energy decreases with increasing temperature and this dependence is described by the square function. The parameters characterizing this function were obtained for each albumin studied.

\section{Materials and Methods}

The following products of the Sigma (USA) were used in the study: HAS (A 1653), ESA (A 9888), OSA (A 3264) and RSA (A 0639). Albumins were used without further purification for all measurements. Aqueous solutions were prepared by dissolving the crystallized albumins in distilled water. To remove possible undissolved fragments the solutions were treated with filter papers. The samples were cooled in a refrigerator (up to $277 \mathrm{~K}$ ) until just prior to viscometry measurements, when they were warmed from $278 \mathrm{~K}$ to $318 \mathrm{~K}$. The $\mathrm{pH}$ values of thus prepared solutions were as follows: 7.0 for HSA, 7.4 for ESA, 7.05 for OSA and 7.0 for RSA, i.e. they were outside their isoelectric point ( $\mathrm{pI})$. The $\mathrm{pI}$ of the studied albumins is: (4.7-4.95) for HSA, (4.65-4.9) for ESA, (4.6-4.9) for OSA and (4.6-5.3) for RSA (Miller and Gemeiner 1998). The
$\mathrm{pH}$ values of the solutions changed slightly in the whole range of concentrations. The above given values are the average $\mathrm{pH}$. As seen from the above values, the solutions were studied at (or in the vicinity of) neutral $\mathrm{pH}$ (7.0), i.e. in conditions in which serum albumins preserve stable conformation (Ho et al. 1993).

Capillary viscosity measurements were conducted using an Ubbelohde-type microviscometer with a flow time for water of $28.5 \mathrm{~s}$ at $298 \mathrm{~K}$. It was placed in a waterbath controlled thermostatically at $278-318 \mathrm{~K}$ with a precision of $\pm 0.1 \mathrm{~K}$. Flow times were recorded to within $0.1 \mathrm{~s}$. The microviscometer was calibrated using cooled boiled distilled water and the same microviscometer was used for all measurements. Measurements started after a few minutes delay to ensure that the system reached equilibrium. For each concentration, the solution was passed once through the microviscometer before any measurements were made. For most concentrations the viscosity measurements were taken from $278 \mathrm{~K}$ to $318 \mathrm{~K}$ mainly by steps of $5 \mathrm{~K}$. At temperatures slightly higher than $318 \mathrm{~K}$ the thermal denaturation of the studied albumins occurs and the lower the protein concentration, the higher the denaturation temperature. From 5 to 10 flow-time measurements were made on each concentration. The Ubbelohde-type microviscometers guarantee high reproducibility of the results. The errors of the viscosity measurements in the whole experimental range of concentrations were less than $1.5 \%$.

The viscosity of the studied albumins is discussed here in the mono-disperse range, i.e. from low concentrations up to: $369 \mathrm{~kg} / \mathrm{m}^{3}$ for HSA, $367 \mathrm{~kg} / \mathrm{m}^{3}$ for ESA, $320 \mathrm{~kg} / \mathrm{m}^{3}$ for OSA, and $300 \mathrm{~kg} / \mathrm{m}^{3}$ for RSA. For higher concentrations the aggregations of albumins occur and solutions become poly-disperse. The problem is discussed in detail elsewhere (Monkos 2005a, b). Solution densities were measured by weighing. For this purpose, $0.3 \pm 0.001 \mathrm{ml}$ of a solution was weighed with the precision of $\pm 0.1 \mathrm{mg}$. Albumin concentrations were determined using a dry weight method in which the samples were dried at high temperature for several hours. The details of the method are described elsewhere (Monkos and Turczynski 1991).

\section{Results and Discussion}

The physical meaning of the activation energy of viscous flow $\Delta \mathrm{E}$ can be deduced on the basis of applications of the absolute rate theory to the process of flow (Fox et al. 1956; Vinogradov and Malkin 1980). In this theory $\Delta \mathrm{E}$ is identified as the energy required for the jump of a molecule from the cage formed by the nearest neighbours to one of the adjoining cages or as a minimum energy required for a molecule of the solution to escape the influence of its neighbouring molecules. In any liquid, to move from one equilibrium 
position to the next, each molecule has to overcome the potential energy barrier created by neighbouring molecules. The height of this potential energy barrier determines the value of the activation energy. It is assumed that molecules overcome the potential energy barrier in elementary jumps. In the absence of an external force field, these jumps occur constantly in all directions with equal probability. The application of the external force field causes the potential energy barrier to decrease in the direction of the force action and to increase in the opposite direction. In consequence, there is higher probability of jumps in the direction of the force action than in the opposite direction.

The value of activation energy of viscous flow $\Delta \mathrm{E}$ can be obtained experimentally from measurements of liquid viscosity at different temperatures and from the slope of the line that represents the dependence of $\ln \eta$ on $\mathrm{T}^{-1}$. This method was successfully applied to many liquids when the viscosity measurements were conducted in a relatively narrow range of temperatures (Hayakawa et al. 1991; Bourret et al. 1994; Lopez da Silva et al. 1994; Jauregui et al. 1995; de Paula and Rodrigues 1995; Kar and Arslan 1999; de Vasconcelos et al. 2000; Desbrieres 2002; Kamimura et al. 2006; Durand 2007; Knoben et al. 2007). Linear dependence of $\ln \eta$ on $\mathrm{T}^{-1}$ means that the activation energy is constant. In fact, even in a narrow range of temperatures, the dependence of $\ln \eta$ on $\mathrm{T}^{-1}$ is only approximately linear. It means that thus obtained activation energy is only an average value from the studied range of temperatures.

Figure 1 shows the results of viscosity measurements for HSA aqueous solution for the concentration of $\mathrm{c}=$ $369 \mathrm{~kg} / \mathrm{m}^{3}$. It can be seen that the plot of $\ln \eta$ versus $\mathrm{T}^{-1}$ is nonlinear, which means that $\Delta \mathrm{E}$ depends on temperature. To obtain $\Delta \mathrm{E}$ value at each particular temperature, a more precise definition has to be applied. In the case of solutions, when activation energy depends on both temperature and concentration, it has the following form:

$$
\Delta E(c, T)=R \frac{d \ln \eta(c, T)}{d T^{-I}}
$$

So, the functional dependence of the viscosity on temperature, describing such dependence from a freezing point up to the temperature of denaturation, is necessary. Such dependence is described by a slightly modified Arrhenius equation (Monkos 1996):

$$
\eta(c, T)=\exp \left[-B_{s}(c)+D_{s}(c) T+\frac{\Delta E_{s}(c)}{R T}\right]
$$

in which $\mathrm{B}_{\mathrm{s}}(\mathrm{c}), \mathrm{D}_{\mathrm{s}}(\mathrm{c})$ and $\Delta \mathrm{E}_{\mathrm{s}}(\mathrm{c})$ are the parameters which depend on the concentration of the solution.

This equation was successfully applied to the description of viscosity dependence on temperature for many types of proteins, for temperatures from the neighbourhood of the solution freezing point up to the vicinity of the denaturation

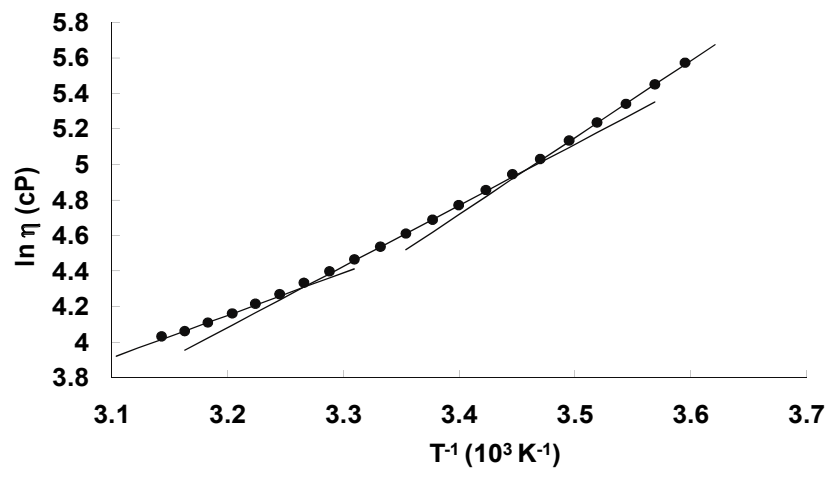

Figure 1. Arrhenius plot showing the temperature dependence of the viscosity of HSA aqueous solution for the concentration $\mathrm{c}=369 \mathrm{~kg} / \mathrm{m}^{3}$. • experimental points; straight lines show different slopes at different temperatures.

temperature of the studied proteins (Monkos 2007a). Moreover, when water viscosity values are taken from standard physicochemical tables, it is easy to show that in this case the equation, analogous to the one above, describes very well the viscosity-temperature dependence from $273 \mathrm{~K}$ up to $373 \mathrm{~K}$. The values of water viscosity obtained on the basis of such equation differ from the experimental values by no more than $1 \%$. Equation (3) (or a similar one to it) can be applied to the description of viscosity-temperature dependence at a wide range of temperatures - both for solutions and one-component liquids. In the case of solutions, the parameters $\mathrm{B}_{\mathrm{s}}(\mathrm{c}), \mathrm{D}_{\mathrm{s}}(\mathrm{c})$ and $\Delta \mathrm{E}_{\mathrm{s}}(\mathrm{c})$ have to be calculated separately for each concentration. The function from Eq. (3) with parameters $\mathrm{B}_{\mathrm{s}}(\mathrm{c}), \mathrm{D}_{\mathrm{s}}(\mathrm{c})$ and $\Delta \mathrm{E}_{\mathrm{s}}(\mathrm{c})$ calculated on the basis of the least squares method (Monkos 1996) gives a very good fit to the experimental points over the whole range of temperature for globular and non-globular proteins (Monkos 2007a) and, in particular, for the studied albumins (Monkos 2004, 2005a,b).

The function from relation (3) can then be inserted into the Eq. (2). After differentiation and simple transformations it is possible to obtain the temperature dependence of the activation energy of viscous flow of a solution:

$$
\Delta E(c, T)=\Delta E_{s}(c)-R D_{s}(c) T^{2}
$$

It appears that the activation energy of the viscous flow for a solution at a given concentration decreases with increasing temperature according to the square function. At the same time, the above formula enables clear physical interpretation of the two parameters of the modified Arrhenius equation: $\Delta \mathrm{E}_{\mathrm{s}}(\mathrm{c})$ denotes the activation energy at $\mathrm{T}=0 \mathrm{~K}$ and $\mathrm{D}_{\mathrm{s}}(\mathrm{c})$ describes the rate at which the activation energy decreases with increasing temperature. The values of $\Delta \mathrm{E}(\mathrm{c}, \mathrm{T})$ for HSA at three temperatures, calculated from the above relation, 


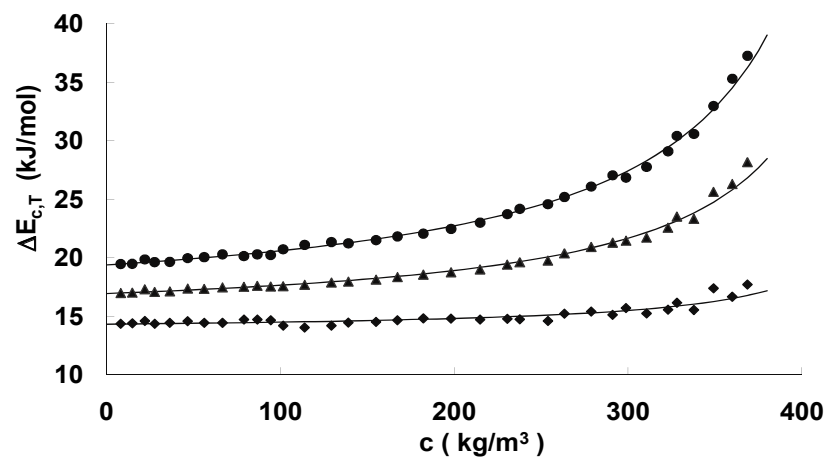

Figure 2. Plot of the solution activation energy $\Delta \mathrm{E}(\mathrm{c}, \mathrm{T})$ versus concentration $\mathrm{c}$ at $\mathrm{T}=278 \mathrm{~K}(\bullet), \mathrm{T}=298 \mathrm{~K}(\boldsymbol{\Delta})$ and $\mathrm{T}=318 \mathrm{~K}(\bullet)$ for HSA. Experimental points were obtained on the basis of Eq. (4); the curves show the fit according to Eq. (7) with the parameters: $\alpha=5.093 \times 10^{6} \mathrm{~kg} / \mathrm{m}^{3}, \xi=2.15 \times 10^{-3} \mathrm{~m}^{3} / \mathrm{kg}$ and $\Delta \mathrm{E}_{\mathrm{p}}(\mathrm{T})=4.876 \times$ $10^{4} \mathrm{~kJ} / \mathrm{mol}, \Delta \mathrm{E}_{\mathrm{W}}(\mathrm{T})=19.39 \mathrm{~kJ} / \mathrm{mol}$ at $\mathrm{T}=278 \mathrm{~K} ; \Delta \mathrm{E}_{\mathrm{p}}(\mathrm{T})=2.863 \times$ $10^{4} \mathrm{~kJ} / \mathrm{mol}, \Delta \mathrm{E}_{\mathrm{w}}(\mathrm{T})=16.3 \mathrm{~kJ} / \mathrm{mol}$ at $\mathrm{T}=298 \mathrm{~K} ; \Delta \mathrm{E}_{\mathrm{p}}(\mathrm{T})=7.103 \times$ $10^{4} \mathrm{~kJ} / \mathrm{mol}, \Delta \mathrm{E}_{\mathrm{w}}(\mathrm{T})=14.33 \mathrm{~kJ} / \mathrm{mol}$ at $\mathrm{T}=318 \mathrm{~K}$.

are shown in Fig. 2, and for RSA at $\mathrm{T}=278 \mathrm{~K}$, OSA at $\mathrm{T}=$ $283 \mathrm{~K}$ and $\mathrm{ESA}$ at $\mathrm{T}=288 \mathrm{~K}$ in Fig. 3 . In the latter, different temperatures were chosen to avoid partial overlapping of the results.

Viscosity measurements for previously studied proteins showed that the parameters $B_{s}(c), D_{s}(c)$ and $\Delta E_{s}(c)$ depend on concentration in the same manner: they monotonically increase with increasing concentration (Monkos 2007a). Based on the assumption that each of them is a superposition

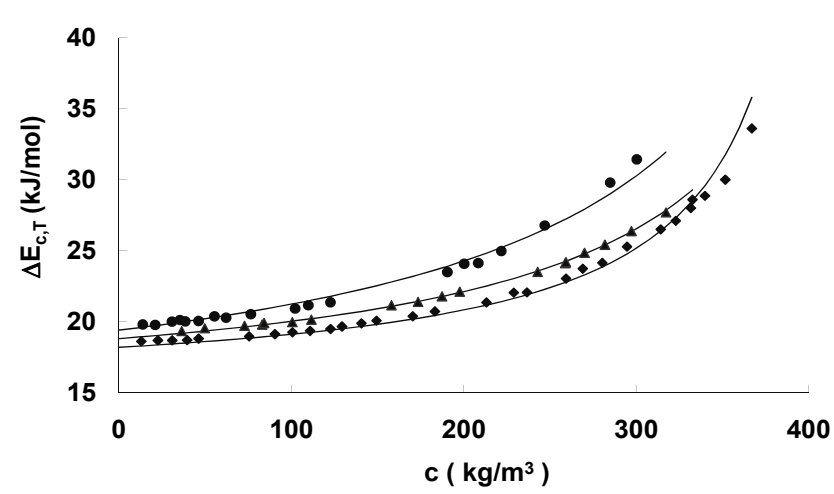

Figure 3. Plot of the solution activation energy $\Delta \mathrm{E}(\mathrm{c}, \mathrm{T})$ versus concentration $\mathrm{c}$ for RSA at $\mathrm{T}=278 \mathrm{~K}(\bullet)$, for OSA at $\mathrm{T}=283 \mathrm{~K}(\boldsymbol{\Delta})$ and for ESA at $\mathrm{T}=288 \mathrm{~K}(\bullet)$. Experimental points were obtained on the basis of Eq. (4); the curves show the fit according to Eq. (7) with the parameters: $\alpha=4.988 \times 10^{6} \mathrm{~kg} / \mathrm{m}^{3}$ and $\xi=1.98 \times 10^{-3}$ $\mathrm{m}^{3} / \mathrm{kg}, \Delta \mathrm{E}_{\mathrm{p}}(\mathrm{T})=7.35 \times 10^{4} \mathrm{~kJ} / \mathrm{mol}, \Delta \mathrm{E}_{\mathrm{w}}(\mathrm{T})=19.39 \mathrm{~kJ} / \mathrm{mol}$ for $\mathrm{RSA} ; \xi=2.08 \times 10^{-3} \mathrm{~m}^{3} / \mathrm{kg}, \Delta \mathrm{E}_{\mathrm{p}}(\mathrm{T})=4.827 \times 10^{4} \mathrm{~kJ} / \mathrm{mol}, \Delta \mathrm{E}_{\mathrm{w}}(\mathrm{T})=$ $18.79 \mathrm{~kJ} / \mathrm{mol}$ for OSA $\xi=2.32 \times 10^{-3} \mathrm{~m}^{3} / \mathrm{kg}, \Delta \mathrm{E}_{\mathrm{p}}(\mathrm{T})=3.507 \times 10^{4}$ $\mathrm{kJ} / \mathrm{mol}, \Delta \mathrm{E}_{\mathrm{W}}(\mathrm{T})=18.18 \mathrm{~kJ} / \mathrm{mol}$ for ESA. of an appropriate parameter for water and dissolved proteins, the following relations for the parameters present in the Eq. (4), were obtained (Monkos 1996):

$$
\begin{aligned}
& \Delta E_{s}(c)=\frac{c}{\alpha-\beta c}\left(\Delta E_{p}-\Delta E_{w}\right)+\Delta E_{w} \\
& D_{s}(c)=\frac{c}{\alpha-\beta c}\left(D_{p}-D_{w}\right)+D_{w}
\end{aligned}
$$

in which $\alpha=\rho_{\mathrm{w}} \mathrm{M}_{\mathrm{h}} / \mathrm{M}_{\mathrm{w}}$ and $\beta=\alpha \xi-1$. The quantities $\rho_{\mathrm{w}}, \xi$, $\mathrm{M}_{\mathrm{h}}$ and $\mathrm{M}_{\mathrm{w}}$ mean water density in $\mathrm{kg} / \mathrm{m}^{3}$, effective specific volume of a protein and molecular masses of the dissolved protein and water, respectively. The effective specific volume is the constant of proportionality between the effective molar volume and the molar mass of a macrosolute. The parameters $\Delta \mathrm{E}_{\mathrm{p}}$ and $\mathrm{D}_{\mathrm{p}}$ are connected with dissolved proteins and $\Delta \mathrm{E}_{\mathrm{w}}$ and $\mathrm{D}_{\mathrm{w}}$ with water. In particular, $\Delta \mathrm{E}_{\mathrm{p}}$ and $\Delta \mathrm{E}_{\mathrm{w}}$ denote the activation energy of proteins and water, respectively. It is worth noting that the dependence of solution activation energy on concentration has, so far, been investigated by very few authors (Jauregui et al. 1995; Kar and Arslan 1999; de Vasconcelos et al. 2000; Desbrieres 2002; Durand 2007). In each case the authors showed that the activation energy of the solution increased with increasing concentration. The functional description of such dependence was proposed only by Durand (2007). However, the obtained fit to the experimental values is not the best one (see Durand 2007, Fig. 7). Contrary to this, the Eq. (5), applied to the globular protein aqueous solutions, describes the concentration dependence of the activation energy at a wide range of concentrations in a very good way (Monkos 2007a).

At $\mathrm{c}=0$, the above equations give $\Delta \mathrm{E}_{\mathrm{s}}(\mathrm{c})=\Delta \mathrm{E}_{\mathrm{w}}$ and $\mathrm{D}_{\mathrm{s}}(\mathrm{c})$ $=\mathrm{D}_{\mathrm{W}}$. At temperatures ranging from $278 \mathrm{~K}$ to $318 \mathrm{~K}$ the values for water are: $\Delta \mathrm{E}_{\mathrm{w}}=35.8 \mathrm{~kJ} / \mathrm{mol}$ and $\mathrm{D}_{\mathrm{w}}=2.55 \times$ $10^{-2} \mathrm{~K}^{-1}$. The pairs of parameters $\left(\Delta \mathrm{E}_{\mathrm{p}}, \xi\right)$ and $\left(\mathrm{D}_{\mathrm{p}}, \xi\right)$ in equations (5) and (6) can be calculated when the molecular mass of hydrated proteins is known. This quantity is the sum of the molecular mass of unhydrated protein $M_{p}$ and the mass of hydration shell of water surrounding the protein molecules in solution: $\mathrm{M}_{\mathrm{h}}=\mathrm{M}_{\mathrm{p}}(1+\delta)$, where $\delta$ means the amount of grams of water associated with the protein per gram of protein. When the molecular mass of hydrated proteins is known, the parameters $\Delta \mathrm{E}_{\mathrm{p}}, \mathrm{D}_{\mathrm{p}}$ and $\xi$ in equations (5) and (6) can be calculated by using once more the least squares method. Thus obtained values for the studied albumins were presented in an earlier study (Monkos 2004; 2005a,b).

The activation energy of a solution, at each individual temperature $\mathrm{T}$, can also be treated as a superposition of the activation energy of dissolved protein molecules at this temperature $\Delta \mathrm{E}_{\mathrm{p}}(\mathrm{T})$ and water molecules at the same tem- 
perature $\Delta \mathrm{E}_{\mathrm{W}}(\mathrm{T})$. This leads to the relation analogous to that presented in Eq. (5):

$$
\Delta E(c, T)=\frac{c}{\alpha-\beta c}\left[\Delta E_{p}(T)-\Delta E_{w}(T)\right]+\Delta E_{w}(T)
$$

It is obvious that at $c=0$ the parameters in the modified Arrhenius Eq. (3) are: $\mathrm{B}_{\mathrm{s}}(\mathrm{c})=\mathrm{B}_{\mathrm{w}}, \mathrm{D}_{\mathrm{s}}(\mathrm{c})=\mathrm{D}_{\mathrm{w}}, \Delta \mathrm{E}_{\mathrm{s}}(\mathrm{c})=\Delta \mathrm{E}_{\mathrm{w}}$ and this gives the viscosity-temperature relationship for water. In this case it is possible to obtain, on the basis of Eq. (2), the relation analogous to that presented in Eq. (4). It allows calculation of the activation energy for water molecules at one given temperature:

$$
\Delta E_{w}(T)=\Delta E_{w}-R D_{w} T^{2}
$$

The values of the activation energy of water, calculated from the above relation, change from $\Delta \mathrm{E}_{\mathrm{w}}(\mathrm{T})=19.39 \mathrm{~kJ} / \mathrm{mol}$ $(\mathrm{T}=278 \mathrm{~K})$ up to $\Delta \mathrm{E}_{\mathrm{w}}(\mathrm{T})=14.33 \mathrm{~kJ} / \mathrm{mol}(\mathrm{T}=318 \mathrm{~K})$. When $\Delta \mathrm{E}_{\mathrm{W}}(\mathrm{T})$ in Eq. (7) is given, the only unknown parameter is $\Delta \mathrm{E}_{\mathrm{p}}(\mathrm{T})$ and it can be obtained by using once more the least squares method. The results of such calculations are shown in Fig. 4. At the same time, Figs. 2 and 3 show that the curves obtained on the basis of formula (7) give good fit to the values obtained from Eq. (4).

Fig. 4 shows that the activation energy of viscous flow for all studied albumins decreases with increasing temperature. Taking into account the fact that the activation energy, at any individual temperature, both for solutions (Eq. 4) and water (Eq. 8) decreases with increasing temperature according to the square function, it can be assumed that the same function also describes the temperature dependence of the activation energy for the dissolved proteins, namely: $\Delta \mathrm{E}_{\mathrm{p}}(\mathrm{T})=\mathrm{u}-\mathrm{RwT}^{2}$. The adjustable parameters " $\mathrm{u}$ " and " $\mathrm{w}$ " can be obtained by applying the least squares method and taking into account the values of $\Delta \mathrm{E}_{\mathrm{p}}(\mathrm{T})$ obtained for the

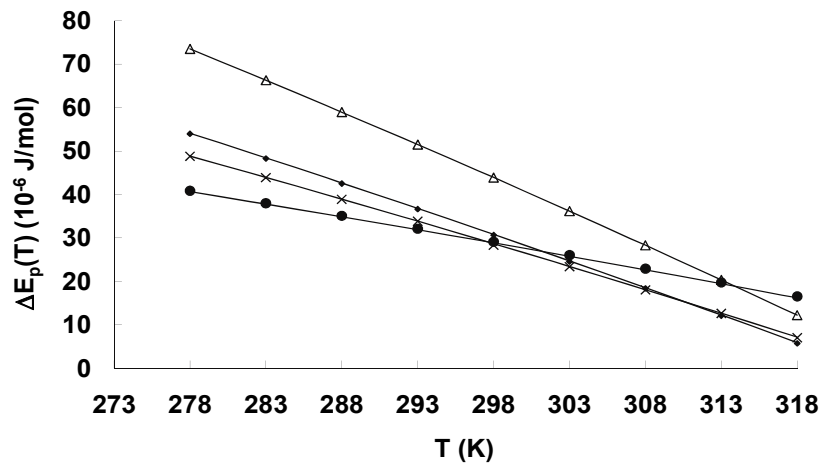

Figure 4. Plot of the activation energy of viscous flow $\Delta \mathrm{E}_{\mathrm{p}}(\mathrm{T})$ versus temperature for RSA $(\Delta)$, OSA $(\bullet)$, HAS $(\times)$ and ESA $(\bullet)$. Points have been obtained from Eq. (7) in which $\Delta \mathrm{E}_{\mathrm{p}}(\mathrm{T})$ is the adjustable parameter. The curves show the fit according to Eq. (9) with: $\Delta \mathrm{E}_{\mathrm{p}}=$ $2.72 \times 10^{5} \mathrm{~kJ} / \mathrm{mol}$ and $\mathrm{D}_{\mathrm{p}}=309 \mathrm{~K}^{-1}$ for RSA, $\Delta \mathrm{E}_{\mathrm{p}}=2.1 \times 10^{5} \mathrm{~kJ} /$ mol and $\mathrm{D}_{\mathrm{p}}=243 \mathrm{~K}^{-1}$ for OSA, $\Delta \mathrm{E}_{\mathrm{p}}=1.84 \times 10^{5} \mathrm{~kJ} / \mathrm{mol}$ and $\mathrm{D}_{\mathrm{p}}=$ $210 \mathrm{~K}^{-1}$ for HSA and $\Delta \mathrm{E}_{\mathrm{p}}=1.2 \times 10^{5} \mathrm{~kJ} / \mathrm{mol}$ and $\mathrm{D}_{\mathrm{p}}=123 \mathrm{~K}^{-1}$ for ESA.

studied albumins from relation (7). Thus obtained parameters are gathered in Table 1. It can be seen that, for each studied albumin, there are only small differences between these parameters (in the range of estimated errors) and the values of $\Delta \mathrm{E}_{\mathrm{p}}$ and $\mathrm{D}_{\mathrm{p}}$ obtained earlier for these albumins. So, we hypothesize that the following relation is fulfilled:

$$
\Delta E_{p}(T)=\Delta E_{p}-R D_{p} T^{2}
$$

Fig. 4 shows a plot of the activation energy of the studied albumins calculated from Eq. (7) vs. temperature and the curves obtained by using Eq. (9). A very good accordance of the fitting curves with the experimental points strongly

Table 1. Hydrodynamic parameters for the studied albumins

\begin{tabular}{lcccc}
\hline & ESA $^{\mathrm{a}}$ & HSA $^{\mathrm{b}}$ & OSA $^{\mathrm{c}}$ & RSA $^{\mathrm{a}}$ \\
\hline$\xi\left(10^{3} \mathrm{~m}^{3} / \mathrm{kg}\right)$ & 2.32 & 2.15 & 2.08 & 1.98 \\
$\Delta \mathrm{E}_{\mathrm{p}}\left(10^{-5} \mathrm{~kJ} / \mathrm{mol}\right)$ & $1.27 \pm 0.07$ & $1.86 \pm 0.08$ & $2.13 \pm 0.09$ & $2.66 \pm 0.12$ \\
$\mathrm{u}\left(10^{-5} \mathrm{~kJ} / \mathrm{mol}\right)$ & $1.20 \pm 0.01$ & $1.84 \pm 0.01$ & $2.10 \pm 0.02$ & $2.72 \pm 0.01$ \\
$\mathrm{D}_{\mathrm{p}}\left(\mathrm{K}^{-1}\right)$ & $122 \pm 5.9$ & $215 \pm 9.9$ & $245 \pm 7.3$ & $320 \pm 18$ \\
$\mathrm{w}\left(\mathrm{K}^{-1}\right)$ & $123 \pm 0.1$ & $210 \pm 0.2$ & $243 \pm 0.2$ & $309 \pm 0.3$ \\
$\mathrm{a}_{\mathrm{h}}(\mathrm{nm})$ & 7.16 & 8.2 & 7.41 & 7.75 \\
$\mathrm{~b}_{\mathrm{h}}(\mathrm{nm})$ & 2.27 & 2.1 & 2.42 & 2.39 \\
$\mathrm{R}_{\mathrm{h}}(\mathrm{nm})$ & 3.74 & 3.89 & 3.94 & 4 \\
\hline
\end{tabular}

ESA, equine serum albumin; RSA, rabbit serum albumin; HAS, human serum albumin; OSA, ovine serum albumin; $\xi$, effective specific volume; $\Delta E_{p}$, activation energy of viscous flow; $D_{p}$, rate of decreasing of the activation energy with increasing temperature; $a_{h}, b_{h}, a_{a i n}$ semi-axes equine serum albumin (ESA) and rabbit serum albumin (RSA). The parameters " $u$ " and "w" obtained as adjustable parameters in equation $\Delta \mathrm{E}_{\mathrm{p}}(\mathrm{T})=\mathrm{u}-\mathrm{RwT}^{2}$. The hydrodynamic radius $\mathrm{R}_{\mathrm{h}}$ for the studied albumins calculated from relation (10). Results were taken from the literature: ${ }^{\mathrm{a}}$ Monkos 2005a, ${ }^{\mathrm{b}}$ Monkos 2004, ${ }^{\mathrm{c}}$ Monkos 2005b. 
suggests that the activation energy of the viscous flow of a protein at any concrete temperature can be calculated from the Eq. (9), if the parameters $\Delta E_{p}$ and $D_{p}$ are known. They should be calculated from Eq. (5) and (6). It should be noted that the correctness of the relation analogous to (9) has also been proved for ovalbumin (Monkos 2007b). This suggests that, the relation (9) is a universal one, at least for proteins.

Fig. 4 shows that the rate at which the activation energy decreases with increasing temperature differs for different albumins. Because of that the ratio of $\Delta \mathrm{E}_{\mathrm{p}}(\mathrm{T})$ at $278 \mathrm{~K}$ and $318 \mathrm{~K}$, for each albumin, is quite different (Table 2). For instance, for RSA $\Delta \mathrm{E}_{\mathrm{p}}(\mathrm{T})$ at $278 \mathrm{~K}$ is about 6 times greater than at $318 \mathrm{~K}$, but for ESA $\Delta \mathrm{E}_{\mathrm{p}}(\mathrm{T})$ at $278 \mathrm{~K}$ is only about 2.5 times greater than at $318 \mathrm{~K}$. It is also worth noting that ESA has, at $278 \mathrm{~K}$, the lowest value of $\Delta \mathrm{E}_{\mathrm{p}}(\mathrm{T})$ from the studied albumins but at $318 \mathrm{~K}$ the value is the highest. Which factors can be responsible for such temperature related changes of the activation energy?

It is well-known that the activation energy of viscous flow depends on molecular mass (Vinogradov and Malkin 1980). However, the molecular mass of mammalian serum albumins is similar (or identical). So, in order to explain which factors, in this case, influence the rate of the decrease in the activation energy with increasing temperature some other factors should be taken into consideration. It is interesting to compare the changes in the activation energy of the studied albumins with the changes in the mean energy of translational heat motion of molecules $<\mathrm{E}>$. This energy is known to be independent of molecular mass and to be equal to $<\mathrm{E}>=1.5 \mathrm{kT}$ ( $\mathrm{k}$ is Boltzmann constant). At the studied range of temperatures $\langle\mathrm{E}\rangle$ increases from $5.76 \times 10^{-21} \mathrm{~J}(\mathrm{~T}=$ $278 \mathrm{~K})$ to $6.59 \times 10^{-21} \mathrm{~J}(\mathrm{~T}=318 \mathrm{~K})$. So, at $\mathrm{T}=318 \mathrm{~K}<\mathrm{E}>$ is only 1.14 times greater than at $\mathrm{T}=278 \mathrm{~K}$. It means that this factor cannot be responsible for the great temperature changes of the activation energy of albumins.

As shown in the previous paper (Monkos 2007a), the activation energy, for a given protein, reaches the maximum value at the $\mathrm{pI}$. The $\mathrm{pH}$ values of the studied albumin solutions were higher than their $\mathrm{pI}$ values. In this case, repulsive interactions between net charges of the albumins molecules partially balance the attractive dipole-dipole interactions between their dipole moments and the total electrostatic interactions between albumins molecules are weak. This suggests that molecular interactions cannot explain such great differentiation in the changes of activation energy of albumins with temperature. The additional argument supporting the above statement comes from the analysis of the intrinsic viscosity $[\eta]$ and the Huggins coefficient $k_{1}$. The intrinsic viscosity is a measure of the contribution of a protein to the viscosity of the solution in which it is dissolved and depends on protein-solvent interactions (Pamies et al. 2008). This quantity, at temperatures ranging from $278 \mathrm{~K}$ to $318 \mathrm{~K}$, was obtained previously for all investigated albumins (Monkos
Table 2. The ratio of the activation energy of viscous flow $\Delta \mathrm{E}_{\mathrm{p}}(\mathrm{T})$, the intrinsic viscosity and the Huggins coefficient at two temperatures for the studied albumins

\begin{tabular}{lcccc}
\hline & RSA $^{\mathrm{a}}$ & OSA $^{\mathrm{c}}$ & HSA $^{\mathrm{b}}$ & ESA $^{\mathrm{a}}$ \\
\hline$\Delta \mathrm{E}_{\mathrm{p}, \mathrm{T} 1} / \Delta \mathrm{E}_{\mathrm{p}, \mathrm{T} 2}$ & 6.02 & 9.46 & 6.87 & 2.47 \\
{$[\eta]_{\mathrm{T} 1} /[\eta]_{\mathrm{T} 2}$} & 1.07 & 1.08 & 1.06 & 1.1 \\
$\left(\mathrm{k}_{1}\right)_{\mathrm{T} 2} /\left(\mathrm{k}_{1}\right)_{\mathrm{T} 1}$ & 1.03 & 1.04 & 1.07 & 1.05 \\
\hline
\end{tabular}

$\Delta \mathrm{E}_{\mathrm{p}}$, the activation energy of viscous flow; [ $\eta$ ], the intrinsic viscosity; k, Huggins coefficient; T1 $=278 \mathrm{~K} ; \mathrm{T} 2=318 \mathrm{~K}$; ESA, equine serum albumin; RSA, rabbit serum albumin; HAS, human serum albumin; OSA, ovine serum albumin. Results were taken from the literature: ${ }^{\mathrm{a}}$ Monkos 2005a, ${ }^{\mathrm{b}}$ Monkos 2004, ${ }^{\mathrm{c}}$ Monkos 2005b.

$2004 ; 2005 a, b)$. The obtained values of the intrinsic viscosity decrease monotonically with increasing temperature. The ratio of [ $\eta]$ at $278 \mathrm{~K}$ and $318 \mathrm{~K}$ is given in Table 2 . The values of this ratio are only slightly higher than 1 , and are nearly identical for all studied albumins. The Huggins coefficient, in turn, represents the quantitative measure of the intermolecular interactions (Dreval et al. 1973). Its values increase monotonically with increasing temperature for all albumins studied here (Monkos 2004; 2005a,b). The ratio of $\mathrm{k}_{1}$ at $318 \mathrm{~K}$ and $278 \mathrm{~K}$ is presented in Table 2 . It can be seen that $\mathrm{k}_{1}$ changes only insignificantly with temperature. This suggests that the intermolecular interactions of albumins in solutions outside the $\mathrm{pI}$ change with temperature very slightly (if any). For solutions with strongly interacting molecules the Huggins coefficient sharply increases with increasing temperature (Desbrieres et al. 1996). In Table 2 the ratio of the activation energy of the studied albumins at $278 \mathrm{~K}$ and $318 \mathrm{~K}$ is also presented. It appears that the changes of $[\eta]$ and $k_{1}$ with temperature are very small in comparison with the changes of $\Delta \mathrm{E}_{\mathrm{p}}(\mathrm{T})$ with temperature. This strongly suggests that the temperature changes of the activation energy of albumins in solutions outside of $\mathrm{pI}$ are not caused by protein-solvent and protein-protein interactions.

However, the influence of some hydrodynamic factors on the activation energy can also be considered. At first approximation, it can be assumed that native albumin molecules are the prolate ellipsoids of revolution with one long semi-axis $\left(a_{h}\right)$ and two shorter semi-axes $\left(b_{h}\right)$. The numerical values of $a_{h}$ and $b_{h}$ of such modeled hydrated albumins are presented in Table 1. When considering of translational movements of proteins in a solution it appears that the hydrodynamic radius $\left(R_{h}\right)$ of proteins plays the essential role. It is connected with the main semi-axes according to the relation given by Perrin (1936):

$$
R_{h}=\frac{\sqrt{a_{h}^{2}-b_{h}^{2}}}{\ln \left(\frac{a_{h}+\sqrt{a_{h}^{2}-b_{h}^{2}}}{b_{h}}\right)}
$$


The hydrodynamic radius of the studied albumins, calculated from the above equation, is presented in Table 1. The results obtained show that both $\Delta \mathrm{E}_{\mathrm{p}}$ and $\mathrm{D}_{\mathrm{p}}$ increase with increasing $R_{h}$. In both cases the relation is non-linear. To establish the analytical dependence of those quantities, measurements for proteins with broad distribution of the hydrodynamic radius are necessary. This will be the subject of further investigations.

All hydrodynamic methods are low-resolution ones. It means that hydrodynamic quantities obtained for proteins on the basis of these methods do not depend on the protein state at the atomic level. The hydrodynamic parameters characterizing proteins in solution depend rather on the overall shape or topology of the protein. It should be emphasized that in the vicinity of neutral $\mathrm{pH}$, albumins have compact and stable conformation. This has been proved by using the small angle X-ray scattering (Olivieri and Craievich 1995) and photon correlation spectroscopy technique (Sontum and Christiansen 1997). The results of investigations based on the phosphorescence depolarization technique and hydrodynamic modeling, in turn, show that the size and conformation of albumins do not change with temperature (Ferrer et al. 2001). The protein molecules in solution are surrounded by a hydration shell of water molecules. The "bound" water molecules migrate with the protein and therefore have to be taken into account in calculations of hydrodynamic parameters characterizing the protein. The hydration shell is an unusually dynamic structure. Individual hydration water molecules exchange with bulk water molecules. The mean times in which water molecules do not change their location are in the range ( $1 \mathrm{~ms}-1 \mathrm{~ns})$ for water molecules buried in internal cavities and in the range (50-100 ps) for water adjacent to non-polar groups and polar residues on the surface of a protein (Harding 2001). Although water molecules from hydration shell are in rapid exchange with water in bulk solution, in hydrodynamic methods based on time-averaged properties their sites appear to be fully occupied. Some experimental results show that the level of protein hydration, i.e. the amount of grams of water associated with the protein per one gram of the protein, does not depend on temperature (Takeda et al. 1991; Miura et al. 1994; Ferrer et al. 2001) and solution concentration (Menon and Allen 1990). Because the size, conformation and level of proteins hydration do not change with temperature, the volume of proteins does not change, either. In particular, Takeda et al. have shown, on the basis of measurements of fluorescence anisotropy of labeled bovine serum albumin, that the protein volume remains unchanged up to the temperature of denaturation. Moreover, it has been proved experimentally, for native bovine and HSA, that the hydrodynamic radius does not depend on solution $\mathrm{pH}$ and temperature (Jachimska et al. 2008). These experimental results clearly show that the changes of activation energy of viscous flow of proteins with temperature cannot be caused by the temperature-induced changes of size, volume or hydrodynamic radius of proteins because those quantities are temperature independent.

The above presented discussion and the results of the present paper strongly suggest that for the proteins with the same (or similar) molecular mass and in solutions outside their pI, the activation energy of viscous flow is mainly influenced by the value of their hydrodynamic radius. This is an interesting problem not only in the case of viscous flow of liquids in physiological and non-physiological conditions but also for other activated processes like, for instance, those of chemical and/or biochemical reactions.

\section{Conclusions}

Viscosity of mammalian albumin solutions, analyzed at a sufficiently wide range of temperatures, shows non-Arrhenius behaviour. This means that the activation energy of viscous flow depends on temperature. The viscosity of aqueous solutions of these albumins at temperatures ranging from $278 \mathrm{~K}$ to $318 \mathrm{~K}$, in the vicinity of neutral $\mathrm{pH}$, may be described quantitatively by a modified Arrhenius equation. This equation, along with a precise definition of the activation energy, allows determination of the functional dependence of this quantity on temperature. Simple calculations shows that thus obtained activation energy decreases with increasing temperature according to the two parameters square function. One of the parameters denotes the activation energy at $\mathrm{T}=0 \mathrm{~K}$, and the other one means the rate of a decrease in the activation energy with increasing temperature. For the studied albumins, both parameters were obtained from the analysis of the concentration dependence of the parameters of a modified Arrhenius equation. The values of activation energy of the albumin molecules at a fixed temperature can be calculated, in turn, from the analysis of a solution activation energy on concentration at the same temperature. Activation energy for the studied albumins, calculated in this way decreases from $4.88 \times 10^{4} \mathrm{~kJ} / \mathrm{mol}$ (at $278 \mathrm{~K}$ ) to $7.1 \times 10^{3} \mathrm{~kJ} / \mathrm{mol}$ (at $318 \mathrm{~K}$ ) for HSA, from $4.08 \times$ $10^{4} \mathrm{~kJ} / \mathrm{mol}$ (at $278 \mathrm{~K}$ ) to $1.65 \times 10^{4} \mathrm{~kJ} / \mathrm{mol}$ (at $318 \mathrm{~K}$ ) for ESA, from $5.39 \times 10^{4} \mathrm{~kJ} / \mathrm{mol}\left(\right.$ at $278 \mathrm{~K}$ ) to $5.71 \times 10^{3} \mathrm{~kJ} / \mathrm{mol}$ (at $318 \mathrm{~K}$ ) for OSA and from $7.35 \times 10^{4} \mathrm{~kJ} / \mathrm{mol}$ (at $278 \mathrm{~K}$ ) to $1.22 \times 10^{4} \mathrm{~kJ} / \mathrm{mol}$ (at $318 \mathrm{~K}$ ) for RSA. The analysis of the results obtained shows that the activation energy of viscous flow of the studied albumins molecules also decreases with increasing temperature according to the two parameters square function. The values of the parameters for the albumins studied show substantial differences. However, the analysis of the results suggests that the viscous flow activation energy of serum albumin molecules is mainly influenced by their hydrodynamic radius. 


\section{References}

Bourret E., Ratsimbazafy V., Maury L., Brossard C. (1994): Rheological behavior of saturated polyglycolysed glycerides. J. Pharm. Pharmacol. 46, 538-541

de Paula R.C.M., Rodrigues J.F. (1995): Composition and rheological properties of cashew tree gum, the exudates polysaccharide from Anacardium occidentale L. Carbohydr. Polym. 26, 177-181 doi:10.1016/0144-8617(95)00006-S

Desbrieres J. (2002): Viscosity of semiflexible chitosan solutions: Influence of concentration, temperature, and role of intermolecular interactions. Biomacromolecules 3, 342-349 doi:10.1021/bm010151+

Desbrieres J., Martinez C., Rinaudo M. (1996): Hydrophobic derivatives of chitosan: characterization and rheological behavior. Int. J. Biol. Macromol. 19, 21-28 doi:10.1016/0141-8130(96)01095-1

de Vasconcelos C.L., de Azevedo F.G., Pereira M.R., Fonseca J.L.C. (2000): Viscosity-temperature-concentration relationship for starch-DMSO-water solutions. Carbohydr. Polym. 41, 181-184 doi:10.1016/S0144-8617(99)00078-8

Dimitrova M.N., Matsumura H., Dimitrova A., Neitchev V.Z. (2000): Interaction of albumins from different species with phospholipids liposomes. Multiple binding sites system. Int. J. Biol. Macromol. 27, 187-194 doi:10.1016/S0141-8130(00)00123-9

Dokal M., Carter D.C., Rüker F. (1999): The three recombinant domains of human serum albumin. J. Biol. Chem. 274, 29303-29310

Dreval V.E., Malkin A.Ya., Botvinnik G.O. (1973): Approach to generalization of concentration dependence of zero-shear viscosity in polymer solutions. J. Polym. Sci. 11, 1055-1076

Durand A. (2007): Aqueous solutions of amphiphilic polysaccharides: concentration and temperature effect on viscosity. Eur. Polym. J. 43, 1744-1753 doi:10.1016/j.eurpolymj.2007.02.031

Ercelen S., Klymchenko A.S., Mély Y., Demchenko A.P. (2005): The binding of novel two-color fluorescence probe FA to serum albumins of different species. Int. J. Biol. Macromol. 35, 231-242 doi:10.1016/j.ijbiomac.2005.02.002

Ferrer M.L., Duchowicz R., Carrasco B., de la Torre J. Acuña A.U. (2001): The conformation of serum albumin in solution: a combined phosphorescence depolarization-hydrodynamic modeling study. Biophys. J. 80, 2422-2430 doi:10.1016/S0006-3495(01)76211-X

Fox T.G., Gratch S., Loshaek S. (1956): Viscosity-temperature relationships for polymers in bulk. In: Rheology. (Ed. F. R. Eirich), Vol. 1, pp. 447-457, Academic Press, New York

Gelamo E.L., Silva C.H.T.P., Imasato H., Tabak M. (2002): Interaction of bovine (BSA) and human (HSA) serum albumin with ionic surfactants: spectroscopy and modeling. Biochim. Biophys. Acta 1594, 84-99 doi:10.1016/S0167-4838(01)00287-4

Gun'ko V.M., Goncharuk E.V., Nechypor O.V., Pakhovchishin S.V., Turov V.V. (2006): Integral equation for calculation of distribu- tion function of activation energy of shear viscosity. J. Colloid. Interface Sci. 304, 239-245

doi:10.1016/j.jcis.2006.08.029

Harding S.E. (2001): The hydration problem in solution biophysics: an introduction. Biophys. Chem. 93, 87-91 doi:10.1016/S0301-4622(01)00213-7

Hayakawa E., Furuya K., Kuroda T., Moriyama M., Kondo A. (1991): Viscosity study on the self-association of doxorubicin in aqueous solution. Chem. Pharm. Bull. 39, 1282-1286

Ho J.X., Holowachuk E.W., Norton E.J., Twigg P.D., Carter D.C. (1993): $\mathrm{X}$-ray and primary structure of horse serum albumin (Equus caballus) at 0.27-nm resolution. Eur. J. Biochem. 215, 205-212 doi:10.1111/j.1432-1033.1993.tb18024.x

Jachimska B., Wasilewska M., Adamczyk Z. (2008): Characterization of globular protein solutions by dynamic light scattering, electrophoretic mobility, and viscosity measurements. Langmuir 24, 6866-6872 doi:10.1021/la800548p

Jauregui B., Muñoz M.E., Santamaria A. (1995): Rheology of hydroxyethylated starch aqueous systems. Analysis of gel formation. Int. J. Biol. Macromol. 17, 49-54 doi:10.1016/0141-8130(95)93518-3

Kamimura Y., Kurumada K., Asaba K., Ban-no H., Kambara H., Hiro M. (2006): Evaluation of activation energy of viscous flow of sol-gel derived phenyl-modified silica glass. J. Non-Cryst. Solids 352, 3175-3178 doi:10.1016/j.jnoncrysol.2006.05.020

Kar F., Arslan N. (1999): Effect of temperature and concentration on viscosity of orange peel pectin solutions and intrinsic viscosity - molecular weight relationship. Carbohydr. Polym. 40, 277-284 doi:10.1016/S0144-8617(99)00062-4

Khan R.H., Shabnum M.S. (2001): Effect of sugars on rabbit serum albumin stability and induction of secondary structure. Biochemistry (Moscow) 66, 1280-1285 doi:10.1023/A:1012386029443

Knoben W., Besseling N.A.M., Cohen Stuart M.A. (2007): Rheology of a reversible suprmolecular polymer studied by comparison of the effects of temperature and chain stoppers. J. Chem. Phys. 126, 024907 doi:10.1063/1.2409296

Lopez da Silva J.A., Gonçalves M.P., Rao M.A. (1994): Influence of temperature on the dynamics and steady-shear rheology of pectin dispersions. Carbohydr. Polym. 23, 77-87 doi:10.1016/0144-8617(94)90031-0

Magerramov M.A., Abdulagatov A.I., Azizov N.D., Abdulagatov I.M. (2007): Effect of temperature, concentration, and pressure on the viscosity of pomegranate and pear juice concentrates. Journal of Food Engineering 80, 476-489 doi:10.1016/j.jfoodeng.2006.05.030

Menon R.S., Allen P.S. (1990): Solvent proton relaxation of aqueous solutions of the serum proteins a2-macroglobulin, fibrinogen and albumin. Biophys. J. 57, 389-396 doi:10.1016/S0006-3495(90)82555-8

Miller I., Gemeiner M. (1998): An electrophoretic study on interactions of albumins of different species with immobilized Cibacron Blue F3G A. Electrophoresis 19, 2506-2514 doi:10.1002/elps.1150191425 
Miura N., Asaka N., Shinyashiki N., Mashimo S. (1994): Microwave dielectric study on bound water of globule proteins in aqueous solution. Biopolymers 34, 357-364 doi:10.1002/bip.360340307

Monkos K, Turczynski B. (1991): Determination of the axial ratio of globular proteins in aqueous solution using viscometric measurements. Int. J. Biol. Macromol. 13, 341-344 doi:10.1016/0141-8130(91)90015-M

Monkos K. (1996): Viscosity of bovine serum albumin aqueous solutions as a function of temperature and concentration. Int. J. Biol. Macromol. 18, 61-68 doi:10.1016/0141-8130(95)01057-2

Monkos K. (2004): On the hydrodynamics and temperature dependence of the solution conformation of human serum albumin from viscometry approach. Biochim. Biophys. Acta 1700, 27-34

Monkos K. (2005a): A comparison of solution conformation and hydrodynamic properties of equine, porcine and rabbit serum albumin using viscometric measurements. Biochim. Biophys. Acta 1748, 100-109

Monkos K. (2005b): Determination of some hydrodynamic parameters of ovine serum albumin solutions using viscometric measurements. J. Biol. Phys. 31, 219-232 doi:10.1007/s10867-005-1830-z

Monkos K. (2007a): Studies of proteins solution conformations using viscometric measurements. In: Methods in Protein Structure and Stability Analysis: Conformational Stability, Size, Shape and Surface of protein molecules. (Eds. V.N. Uversky and E.A. Permyakov), pp. 355-387, Nova Science Publishers, NY

Monkos K. (2007b): Temperature dependence of the activation energy of viscous flow for ovalbumin in aqueous solutions. Curr. Top. Biophys. 30, 29-33

Moser P., Squire P.G., O’Konski C.T. (1966): Electric polarization in proteins - dielectric dispersion and Kerr effect. Studies of isoionic bovine serum albumin. J. Phys. Chem. 70, 744-756 doi:10.1021/j100875a023

Olivieri J.R., Craievich A.F. (1995): The subdomain structure of human serum albumin in solution under different $\mathrm{pH}$ condi- tions studied by small angle X-ray scattering. Eur. Biophys. J. 24, 77-84

Pamies R., Hernández J.G., del Carmel López Martínez M., Garcia de la Torre J. (2008): Determination of intrinsic viscosities of macromolecules and nanoparticles. Comparison of single-point and dilution procedures. Colloid. Polym. Sci. 286, 1223-1231 doi:10.1007/s00396-008-1902-2

Perrin F. (1936): Mouvement Brownien d'un ellipsoide. II. Rotation libre de depolarization des fluorescence: translation et diffusion de molecules ellipsoidales. J. Physique Radium 7, 1-11 doi:10.1051/jphysrad:01936007010100

Šoltés L., Sebille B. (1997): Reversible binding interactions between the tryptophan enantiomers and albumins of different animal species as determined by novel high performance liquid chromatographic methods: an attempt to localize the D- and L-tryptophan binding sites on the human serum albumin polypeptide chain by using protein fragments. Chirality 9, 373-379 doi:10.1002/(SICI) 1520-636X(1997)9:4<373::AID-CHIR10>3.0.CO;2-K

Sontum P.S., Christiansen C. (1997): Photon correlation spectroscopy applied to characterization of denaturation and thermal stability of human albumin. J. Pharm. Biomed. Anal. 16, 295-302 doi:10.1016/S0731-7085(97)00032-0

Takeda K., Yoshida I., Yamamoto K. (1991): Changes of fluorescence lifetime and rotational correlation time of bovine serum albumin labeled with 1-dimethylaminonaphthalene-5-sulfonyl chloride in guanide and thermal denaturations. J. Protein Chem. 10, 17-23 doi:10.1007/BF01024651

Tiffany J.M., Koretz J.F. (2002): Viscosity of alpha-crystallin solutions. Int. J. Biol. Macromol. 30, 179-185 doi:10.1016/S0141-8130(02)00018-1

Vinogradov G.V., Malkin A.Ya. (1980): Rheology of Polymers. Mir, Moscow.

Received: October 7, 2010

Final version accepted: December 16, 2010 